\title{
Inmutabilidad y mutabilidad de la significación de las raíces léxicas
}

MARCIAL MORERA

Universidad de La Laguna

Uno de los fenómenos semánticos que más llama la atención cuando se analiza el comportamiento de las raíces léxicas (en realidad, de todo signo primario, o morfema, como prefieren denominarlo los lingüistas norteamericanos) en la realidad concreta del hablar es su enorme versatilidad, su proverbial capacidad para adaptarse a las formas gramaticales y funciones referenciales más heterogéneas, sin alterar lo más mínimo su estructura semántica interna. En efecto, la significación invariante de la raíz léxica, que, dicho de forma muy general, no es otra cosa que la intuición de una forma geométrica (regular o irregular), que nada tiene que ver con esas unidades nocionales que llamamos conceptos, es tan abstracta y tan maleable al contexto, que la misma puede aparecer implicada en palabras o frases que absolutamente nada tengan que ver entre sí (tanto desde el punto de vista gramatical como desde el punto de vista referencial), sin alterar lo más mínimo su estructura semántica básica. Es decir, que la unidad semántico-formal de la raíz no implica, ni mucho menos, unidad conceptual, sino todo lo contrario. Es lo que se aprecia, por ejemplo, en el caso de la raíz española fond-(hond-, fund-), que lo único que parece implicar constante e invariablemente es la forma semántica 'dimensión opuesta a la superficie o cara', y que ha dado lugar a combinaciones gramatical y denotativamente tan distintas como fondo 'parte inferior de una cosa hueca', fondillo 'parte del pantalón correspondiente a las nalgas', fondón 'se aplica a la persona que está un poco gorda', fondista 'deportista en carreras de largo recorrido', profundo 'que penetra mucho o que va hasta muy adentro', funda 'forro, protección de una cosa', honda 'tira de cuero para tirar piedras con violencia', hondo 'que tiene profundidad', hondura 'profundidad de una cosa', hundir 'hacer que algo se vaya por completo al fondo de una masa de agua', fundir 'convertir un sólido en líquido', difundir 'introducir en un cuerpo corpúsculos extraños con tendencia a formar una mezcla homogénea', confundir 'equivocar', profuso 'abundante', refundir 'sumergir en lo más hondo', rehúso 'desecho', rehusar 'rechazar', trasfusión 'acción de trasfundir', fundar 'estribar, apoyar, armar alguna cosa material sobre otra', fundación 'establecimiento y origen de algo', enfundar 'poner algo dentro de una funda', fondear 'reconocer el fondo', fondeadero 'lugar en que se fondea la embarcación', desfondar 'quitar o romper el fondo a una cosa', etc., etc., manteniendo intacta en lo esencial su estructura semántica interna. Es lo que podríamos denominar la inmutabilidad de la forma semántica básica, que, junto con la recursividad propia de los procedimientos gramaticales, hace posible el funcionamiento eficaz del código lingüístico. Si no fuera por esta tendencia a la inmutabilidad, por esta perseverancia del signo en mantener su identidad semántica a toda costa, el código lingüístico sería inviable, porque degeneraría en un conjunto de prácticas caprichosas sometidas al albur de los contextos gramaticales y denotativos y a la subjetividad de los hablantes. Para cumplir cabalmente su función formalizadora de la realidad y su función comunicativa, el 
código lingüístico debe ser lo más estable posible, y a esa estabilidad contribuye en un porcentaje muy alto la resistencia de la significación primaria o de raíz al cambio.

En primer lugar, la forma semántica básica o significación primaria se muestra siempre absolutamente inmutable a la influencia de la significación categorial que se relaciona habitualmente con ella, y que la presenta existiendo de una determinada manera en el universo del discurso. Así, aunque la raíz léxica fond- de nuestro ejemplo aparezca categorizada como sustantivo en las formas fondo, funda, honda, etc., como adjetivo en la forma hondo y como verbo en las formas hundir, fundir, fundar, hondar, etc., su significación primaria o formal 'dimensión opuesta a la superficie o cara' no se ve alterada en lo más mínimo. Lo que realmente diferencia las distintas variantes categoriales de fond- (hond-, fund-) no es la significación primaria, la intuición formal básica, que es en todas las palabras citadas la misma, sino más bien la significación categorial, la forma de presentarse esta intuición geométrica básica en el universo del discurso: en las variantes fondo, funda y honda, la significación primaria 'dimensión opuesta a la superficie o cara' se presenta como objeto independiente, y de ahí que se le interprete como cosa y que pueda desempeñar funciones de sujeto, complemento directo, término de preposición, etc., en los enunciados; en la variante hondo, dicha significación primaria se presenta como 'rasgo simple del sustantivo', y de ahí que se le interprete como cualidad y que aparezca en los textos desempeñando la función sintáctica de atributo; y en las variantes hundir, fundir, fundar y hondar, dicha significación primaria se presenta como proceso, con tiempo interno, y de ahí que se le interprete como acción y que aparezca en los textos desempeñando la función sintáctica de predicado. No hay, por tanto, en estas palabras la más mínima razón semántica para decir que nos encontramos ante unidades léxicas distintas, sino ante meras variantes categoriales de la misma significación léxica o intuición semántica básica.

Exactamente lo mismo se podría decir de la raíz fin-, que, aunque aparezca categorizada como sustantivo en la forma fin, como adjetivo en la forma fino y como verbo en las formas finar, finir, su significación primaria o formal 'límite último de la dimensión sin extensión' se mantiene en todos los casos incólume. Lo que realmente diferencia a estas variantes de finentre sí no es la significación formal o básica, que es en todas las voces citadas exactamente la misma, sino más bien la significación categorial, la forma particular de presentar la mencionada intuición geométrica o espacial en el universo del discurso: en la variante fin, se presenta como objeto independiente, y de ahí que se le interprete como cosa y que pueda desempeñar funciones sintácticas de sujeto, complemento directo, régimen preposicional, etc., en los enunciados; en la variante fino, se presenta como rasgo simple del sustantivo, y de ahí que se le interprete como cualidad y que aparezca en los textos desempeñando la función sintáctica de atributo; y en las variantes finar y finir, se presenta como proceso, con tiempo interno, y de ahí que se les interprete como acción y que aparezcan en los textos desempeñando funciones sintácticas de predicado. No hay, por tanto, ninguna razón semántica para afirmar que fin, fino y finar constituyen tres unidades léxicas distintas, porque lo que las diferencia no es la significación léxica o primaria, la intuición semántica espacial básica, sino la significación categorial, que pertenece al plano gramatical.

En segundo lugar, también resulta absolutamente inmutable la significación formal de las raíces léxicas a la influencia de las distintas experiencias que, en función de la significación categorial que la determine en cada caso, designemos con ella en la realidad concreta del hablar, aunque dichas cosas o experiencias y las nociones a que dan lugar no tengan nada que ver las 
unas con las otras. Así, aunque la variante categorial sustantivo fondo de nuestra raíz léxica fond-se haya especializado en unos casos en la referencia 'parte inferior de una cosa hueca', en otros, en la referencia 'color o dibujo que cubre una superficie y sobre la cual resaltan los adornos, dibujos o manchas de otro u otros colores'; en otros, en la referencia 'caudal o conjunto de bienes que posee una persona o comunidad'; en otros, en la referencia 'parte principal y esencial de algo, en oposición a la forma'; en otros, en la referencia 'resistencia física, reserva de energía corporal para aguantar esfuerzos prolongados'; etc., etc., la significación espacial 'dimensión opuesta a la superficie o cara' de dicha raíz y su significación categorial sustantiva permanecen absolutamente invariables. Lo que realmente diferencia estas cinco aplicaciones designativas del sustantivo fondo no es su significación formal básica, que es en todos los casos citados la misma, sino las condiciones de la designación, el hecho de que en el primer caso la significación primaria 'dimensión opuesta a la superficie o cara' categorizada como sustantivo se aplique a cosas concretas huecas, como recipientes y otras cosas cóncavas; en el segundo, a cuadros o superficies planas con dibujos o manchas; en el tercero, a los bienes de una persona o entidad; en el cuarto, a discursos, escritos, etc.; y en el quinto, a la capacidad física de las personas para practicar determinados deportes. Nos encontramos, por tanto, no ante significados distintos de dicha variante categorial de fond-, sino ante meras orientaciones de sentido, meras sustancializaciones de su única significación formal. ${ }^{1}$

Pongamos otro ejemplo más de este importantísimo problema semántico que nos ocupa. Aunque la variante categorial adjetiva fino de la raíz léxica fin-se haya especializado en la denotación de cualidades tan distintas como 'delgado, esbelto y de facciones delicadas', 'de exquisita educación', 'que hace las cosas con primor y oportunidad', 'astuto, sagaz', 'amoroso, afectuoso', 'delgado, sutil', 'que por su traza, corta el agua con facilidad', 'depurado, acendrado', 'suave, terso', 'delicado y de buena calidad en su especie', 'agudo', 'muy seco', etc., la significación espacial ‘límite último de la dimensión sin extensión’ de dicha raíz y su significación categorial adjetiva no se alteran lo más mínimo. Lo único que realmente parece cambiar en estas doce aplicaciones designativas del adjetivo fino no es su significación formal básica, que es en todos los casos la misma, sino las condiciones de la designación, el hecho de que en los cinco primeros casos se aplique a distintos aspectos de las personas (sus condiciones físicas, su comportamiento social, su forma de trabajar, su forma de resolver problemas complicados y su forma de tratar a las personas, respectivamente) y en los siete restantes a las cosas: objetos agudos, embarcaciones, metales, textura de las cosas, materias, sentidos y vino de Jerez, también respectivamente. No se trata, por tanto, de significaciones distintas de fino, sino de orientaciones de sentido, de variaciones sustanciales de su verdadera significación invariante.

Los mismos ejemplos aducidos nos ponen claramente de manifiesto que las distintas variantes denotativas de las variantes categoriales de una raíz pueden presentar formalización fónica propia, sin por ello dejar de ser variantes de su unidad semántica. Es lo que ocurre en los casos citados de hundir, fundir, fundar, hondar y fondar, que, semánticamente, solo se diferencian en la denotación, pero no en la significación formal, que es en todas estas palabras la misma: 'dimensión opuesta a la superficie o cara-en proceso'; o en los casos de finar y finir, que igualmente solo se diferencian en la denotación, pero no en la significación formal, que es

${ }^{1}$ He llamado la atención sobre este importante problema de la en absoluto sorprendente heterogeneidad semántica de los elementos del campo de usos de las unidades semánticas en varios artículos anteriores, como Morera (en prensa a y b). 
en ambos casos exactamente la misma: 'límite último de la dimensión sin extensión-en proceso’. ¿Cómo es posible que esto sea así? ¿Cómo es posible que conceptos que disponen de expresión diferenciada sean meras variantes semánticas de una misma forma de contenido? Pues, simplemente, porque, como dijimos más arriba, la significación del signo lingüístico no es de naturaleza conceptual, sino de naturaleza espacial, y esta intuición espacial puede mantenerse (y de hecho se mantiene) incólume aunque cambien los conceptos denotados. A pesar de sus diferencias denotativas y formales, hundir, fundir, fundar, hondar y fondar, por un lado, y finar y finir, por otro, mantienen invariantes sus intuiciones básicas de 'dimensión opuesta a la superficie o cara' y 'límite último de la dimensión sin extensión', respectivamente, y esto convierte a cada serie de las citadas en variantes de expresión en distribución complementaria de la misma unidad semántica: la unidad semántica 'dimensión opuesta a la superficie o cara' y la unidad semántica 'límite último de la dimensión sin extensión'.

En tercer lugar, también se muestra inmune la estructura semántica interna de la raíz léxica a la influencia de la significación morfológica que la determina frecuentemente en la realidad concreta del hablar. Por ejemplo: aunque la mencionada variante categorial sustantiva de nuestra raíz léxica fond-aparezca complementada por el sufijo -illo en la combinación fondillo, por el sufijo -ón en la combinación fondón, por el sufijo -ista en la combinación fondista, etc., su consabida significación formal o invariante 'dimensión opuesta a la superficie o cara' y la significación categorial sustantiva que la determina en estos casos en concreto permanecen de nuevo inmutables. Lo que diferencia realmente a estas variantes morfológicas de la raíz fond- de su base léxica fondo no es la significación primaria descriptiva o básica, que es en toda su familia de palabras la misma, sino más concretamente la complementación morfológica ( $i$. e., la cuantificación interna de esa materia semántica en sí misma cuantitativamente indeterminada) y las consecuencias categoriales que ello pueda acarrear: en la variante fondillo, el complemento morfológico -illo presenta la materia semántica cuantitativamente indeterminada 'dimensión opuesta a la superficie o cara-como objeto independiente' como 'apenas llegando a su límite', o 'disminuido', como quiere la gramática tradicional; en el caso de la variante fondón, el complemento morfológico -ón la presenta 'superando bruscamente su límite', o de forma aumentada, como quiere también la gramática tradicional; y en el caso de la variante fondista, el complemento morfológico -ista la presenta como 'límite de apego activo'. Variantes morfológicas, pues, de la misma significación descriptiva invariante, y no formas léxicas distintas.

Exactamente lo mismo ocurre - por poner otros ejemplos- en el caso de la variante verbal finar (finir) de la raíz fin-, que, aunque aparezca complementada por los sufijos -ado, ito, -able y -ante en las combinaciones finado, finito, finable y finante, su significación formal 'límite último de la dimensión sin extensión' y la significación categorial verbal que la determina en este caso en concreto se mantienen constantes. Lo que diferencia en realidad estas variantes morfológicas de la raíz fin- de su primitivo finar (finir) no es la significación primaria descriptiva o básica, que es en todos los elementos de su familia la misma, sino más concretamente la complementación morfológica y las consecuencias categoriales que ello pueda conllevar: en la variante finado, el complemento morfológico -ado presenta el complejo semántico 'límite último de la dimensión sin extensión-en proceso' como 'extensamente acabado'; en la variante finito, el complemento morfológico -ito lo presenta como 'puntualmente acabado'; en la variante finable, el complemento morfológico - able lo presenta como 'potencialmente acabado'; y en la variante finante, el complemento morfológico -ante lo 
presenta como 'cursivo interno al sujeto'. No hay, por tanto, diferencia en el nivel de la significación primaria de estas palabras, ni en el nivel de su significación categorial de partida, sino en ese componente gramatical que la lingüística denomina complemento morfológico.

En cuarto lugar, también son inocuas para la significación formal de la raíz léxica las designaciones particulares que la misma puede desarrollar en la realidad concreta del hablar en función del complemento morfológico que lo acompañe en cada caso. Así, aunque el mencionado derivado fondón se entienda habitualmente como 'se dice de la persona que está un poco gorda, especialmente por las nalgas', la significación invariante de su raíz y su formalización gramatical (categoría sustantiva y cuantificación 'superación brusca del límite de la materia semántica' del sufijo -ón) permanecen intactos. Lo que realmente diferencia a fondón del resto de las formas de su familia de palabras no es la significación invariante de la raíz, su forma semántica básica, que es en todos los casos la misma, sino el sentido contextual que este derivado ha desarrollado en la realidad concreta del hablar, en función de su aplicación a las cualidades físicas de una persona.

La forma finado, derivada, como sabemos, de la variante verbal de la raíz fin-, se ha especializado en español en la variante conceptual tan particular de 'persona muerta'. Ello no quiere decir, sin embargo, que nos encontremos ante una unidad léxica distinta de la que posee el resto de los miembros de su familia de palabras. Lo que realmente diferencia a finado de finito, finable, finante, etc., no es en realidad su significación primaria descriptiva, que es en todos los casos la misma ('límite último de la dimensión sin extensión'), sino más bien su determinación morfológica y su denotación, condicionada por el hecho extralingüístico de que la misma se predique de la vida de las personas.

En quinto lugar, hay que decir que tampoco se ve afectada en lo más mínimo la significación invariante de la raíz por la complementación sintáctica que la suele determinar ocasionalmente en la realidad concreta del hablar. Por ejemplo: aunque la variante verbal de la raíz léxica fond- (fund-, hund-) aparezca complementada por el prefijo con- en la forma confundir, por el prefijo di- en la forma difundir, por el prefijo in- en la forma infundir, por el prefijo re- en la forma refundir y por el prefijo tras- en la forma trasfundir, la significación invariante de su base léxica y su determinación categorial verbal es en todos los casos la misma: 'dimensión opuesta a la superficie o a la cara-en proceso'. Lo que diferencia en realidad a las formas confundir, difundir, infundir, refundir y transfundir entre sí y con el resto de los miembros de su familia de palabras no es ni la significación primaria ni la significación categorial, sino la complementación sintáctica: que en la combinación confundir, el complemento sintáctico con- presenta la significación invariante 'dimensión opuesta a la superficie o cara-en proceso' situada en una relación de 'acompañamiento positivo'; en la combinación difundir, el complemento sintáctico $d i$ - la presenta situada en una relación de 'movimiento de alejamiento genérico'; en la combinación infundir, el complemento sintáctico in- la presenta situada en una relación de 'ubicación absoluta'; en la combinación refundir, el complemento sintáctico re- la presenta situada en una relación de 'vuelta hacia su origen'; y en la combinación trasfundir, el complemento sintáctico tras- la presenta situado en una relación de 'ubicación en el polo negativo de un punto de referencia dispuesto de forma horizontal'. No se trata, por tanto, de formas léxicas distintas, sino de variantes sintácticas de la misma y única forma semántico-descriptiva.

También la familia de palabras fin- nos proporciona buenos ejemplos de los que comentamos: afinar, confinar, definir y refinar, por poner solo unos cuantos casos, no se 
diferencian tampoco en la significación básica ni en la significación categorial, que es en todos los casos la misma ('límite último de la dimensión sin extensión-en proceso'), sino en la significación sintáctica: en la combinación afinar, el complemento sintáctico $a$ - la presenta situada en una relación de 'término final absoluto de un movimiento de aproximación'; en la combinación confinar, el complemento sintáctico con-, la presenta situada en una relación de 'acompañamiento positivo'; en la combinación definir, el complemento sintáctico de- la presenta situado en una relación de 'movimiento de alejamiento genérico'; y en la combinación refinar, el complemento sintáctico re- la presenta situado en una relación de 'vuelta hacia su origen'. Exactamente igual que antes, variantes sintácticas de una misma forma léxica, y no cuatro unidades léxicas distintas.

Por último, como es natural, tampoco altera lo más mínimo la significación de la raíz las particulares funciones designativas que la misma puede desarrollar en la realidad concreta del hablar, en función de sus diferentes complementos sintácticos. Es lo que se aprecia en el caso de la mencionada variante sintáctica confundir de la forma fundir, que, aunque se ha especializado en esa designación tan particular que los diccionarios al uso suelen definir como 'mezclar cosas materiales o inmateriales unas con otras', en realidad su significación invariante de 'dimensión opuesta a la superficie o cara-en proceso-situado en una relación de acompañamiento positivo’ no se ve alterada lo más mínimo por esta denotación. Lo que diferencia al verbo confundir 'mezclar cosas materiales o inmateriales unas con otras' del resto de los miembros de su familia de palabras no es la significación primaria o básica, la intuición semántico-formal que implica su raíz, sino su denotación.

También el verbo definir presenta un sentido denotativo muy particular, el sentido denotativo de 'fijar con claridad, exactitud y precisión la significación de una palabra o la naturaleza de una persona o cosa'; pero esto no implica que presente una significación léxica particular, distinta de la que se encuentra en la base del resto de los miembros de su familia de palabras. En realidad, lo que diferencia al definir de 'fijar con claridad, exactitud y precisión la significación de una palabra o la naturaleza de una persona o cosa' del resto de los elementos de su familia de palabras no es la significación primaria, que es, como hemos dicho ya, exactamente la misma ('límite último de la dimensión sin extensión'), cuanto la significación gramatical y su orientación de sentido, determinado por el contexto.

Es evidente, por tanto, que no hay más significación léxica o descriptiva que la que está en la raíz, un tipo de significación de naturaleza intuitivo-formal, no de naturaleza conceptual, que presenta una enorme capacidad gramatical y denotativa, sin alterar lo más mínimo su identidad semántica.

Ahora bien, el hecho de que las raíces léxicas presenten tanta resistencia a la influencia del contexto gramatical y del contexto denotativo, que defiendan con tanta tenacidad su estructura semántica de las agresiones externas, no implica, ni mucho menos, que las mismas no puedan alterar su significación invariante a lo largo de la historia de la lengua, y transformarse en unidades léxicas distintas. ${ }^{2}$ Esto que comentamos es precisamente lo que sucedió en el caso de la raíz española lev- 'situación vertical positiva por tener poco peso o consistencia', que, con el tiempo, terminó generando la raíz llev- 'desplazamiento de algo que está con el sujeto hacia un punto distinto de aquel en que se encuentra el yo'; o en el caso de la raíz latina PAND- 'ocupación progresiva de espacio', base del participio de pasado PASSUS, que

\footnotetext{
${ }^{2}$ Para una visión más amplia de este problema, vid. Morera (en prensa a).
} 
terminó transformándose en la raíz léxica románica pas- 'movimiento perfectivo extenso'. A esta posibilidad de las raíces léxicas es a lo que podríamos denominar la mutabilidad de la significación primaria. ¿Cómo cambia realmente la estructura semántica de la raíz? ¿Qué factores concretos contribuyen a su alteración?

Lo primero que hay que decir en relación con este asunto es que la significación invariante de la raíz suele cambiar por razones extralingüísticas, generalmente porque los hablantes, por razones diversas, empiezan a sentir espontáneamente el signo de una manera nueva. En ciertos casos, el desconocimiento del significado de una determinada raíz puede llevar al hablante a identificarla (por etimología popular, como dice la lingüística tradicional) con otra raíz de significante más o menos parecido, dando lugar, por tanto, a una especie de cambio que podríamos llamar por confluencia o convergencia semántica. Es el caso, por ejemplo, de la raíz léxica latina LAT- 'estar escondido', que terminó fundiéndose con la raíz léxica GLATT- 'dar latidos agudos', origen de nuestros latir, latente, etc.

En otros casos, la automatización de la percepción puede llevar al hablante a percibir de forma simultánea, en una misma unidad de representación intuitiva, los dos o más constituyentes semánticos sucesivos o sintagmáticos de una misma palabra. El resultado de ello es que un rasgo semántico (morfológico o sintáctico) que se había añadido independientemente a la raíz termina convirtiéndose en rasgo interno o constitutivo. Es lo que podríamos llamar paradigmatización de rasgos semánticos sintagmáticos. ${ }^{3}$ Esto que comentamos es lo que parece haber sucedido en el caso de la raíz española pas-, procedente, como sabemos, del latín PAssus, participio de pasado del verbo PANDERE 'expandir', que convirtió en paradigmático o interno el rasgo semántico 'aspecto perfectivo' del sufijo de participio de pasado, dando lugar a la nueva significación primaria 'movimiento perfectivo extenso', que es lo que significa constante e invariablemente la raíz pas- (pass-) en las lenguas románicas.

En tercer lugar, por último, la presión de un rasgo espacial del contexto puede llegar a obscurecer o apagar hasta tal punto la significación inherente de la raíz, que al final el hablante termine olvidándose de ella y percibiendo solamente dicho matiz contextual. Es lo que podríamos denominar formalización lingüistica de rasgos semánticos extralingüísticos. Es lo que sucedió, al parecer, en el caso de la mencionada raíz español llev-, que resultó de la formalización semántica del matiz de 'movimiento' que la raíz léxica lev- 'situación de verticalidad positiva por poco peso' llevaba aparejada en determinados contextos de uso.

En todo caso, se ve claro que los cambios gramaticales y denotativos de las raíces léxicas son cambios provocados por razones internas al sistema, cambios motivados por el funcionamiento del sistema mismo. En este sentido, puede decirse que son cambios sistemáticos, cambios sometidos a reglas. Por el contrario, los cambios semánticos que afectan a la significación invariante de la raíz son cambios provocados por circunstancias ajenas al sistema mismo, cambios fortuitos, generalmente provocados por una nueva actitud del hablante ante el signo afectado. En este sentido, se puede decir que no son cambios semánticos inducidos por el funcionamiento del sistema, sino cambios provocados desde fuera que alteran el sistema.

${ }^{3} \mathrm{He}$ desarrollado este mismo asunto por extenso en Morera (2007). 


\section{REFERENCIAS BIBLIOGRÁFICAS}

Morera, Marcial (2007): «El cambio semántico por incorporación sémica», en Pablo Cano et alii, eds., Actas del VI Congreso de Lingüística General, Santiago de Compostela, 2004, Madrid, Arco/Libros, 2, pp. 1221-1228.

_ (en prensa a): «Los cambios semánticos de las raíces léxicas», en Homenaje al profesor Gerd Wotjak, Berlín, pp. 323-331

- (en prensa b): «El Diccionario de familia de palabras de la lengua española: su componente morfológico», en José Carlos Martín Camacho y $\mathrm{M}^{\mathrm{a}}$ Isabel Rodríguez Ponce, eds., II Encuentro de Morfólogos Españoles, Cáceres. pp. 55-66 